\title{
Tunable Microstrip Filters Using Selectively Etched Ferroelectric Thin- Film Varactors for Coupling
}

\author{
Carl H. Mueller, Analex Corporation, Cleveland, OH 44135 (USA) \\ Frederick W. Van Keuls, Ohio Aerospace Institute, Cleveland, OH 44135 (USA) \\ Robert R. Romanofsky, NASA-Glenn Research Center, Cleveland, OH 44135 (USA) \\ Guru Subramanyam, Department of Electrical and Computer Engineering, University of \\ Dayton, Dayton, OH 45469-0226 USA \\ Félix A. Miranda, NASA-Glenn Research Center, Cleveland, OH 44135 (USA)
}

\begin{abstract}
We report on the use of patterned ferroelectric films to fabricate proof of concept tunable one-pole microstrip filters with excellent transmission and mismatch/reflection properties at frequencies up to $24 \mathrm{GHz}$. By controlling the electric field distribution within the coupling region between the resonator and input/output lines, sufficiently high loaded and unloaded $Q$ values are maintained so as to be useful for microstrip filter design, with low mismatch loss. In the $23-24 \mathrm{GHz}$ region, the filter was tunable over a $100 \mathrm{MHz}$ range, the loaded and unloaded Q values were 29 and 68, respectively, and the reflection losses were below $-16 \mathrm{~dB}$, which demonstrates the suitability of these films for practical microwave applications.
\end{abstract}

\section{INTRODUCTION}

Ferroelectric devices have been targeted for use in a variety of tunable microwave applications, such as phase shifters[1-6], filters[7-10], and impedance matching networks[11]. Key reasons for pursuing ferroelectric research are the potential for improved circuit performance with respect to those achieved using more established tuning technologies such as semiconductor varactor diodes for low-loss, tunable devices at $\mathrm{X}$-band $(8-12 \mathrm{GHz})$ and higher frequencies, negligible de power needed for tuning, as well as good RF power handling capabilities[12]. Nevertheless, there are several reasons why development of these devices has not proceeded more quickly. First, the commercial market for high frequency tunable devices does not justify a concentrated, expensive development program. However, as commercial devices expand to higher frequencies and bandwidths, and as electronic devices adopt increasing functionality and become more adaptable, the future for ferroelectric tuning appears promising. Most of the tunable filters realized to date have used the entire ferroelectric thin film layer in microstrip or CPW configurations [7-10]. The coupled lines of the filters were biased to obtain tuning performance of the ferroelectric thin films between the coupled lines. The presence of BST thin film on the entire substrate results in higher insertion loss and poor reflection loss. In this work, we are introducing patterned ferroelectric thin-films in the coupling regions between the feed lines and the resonator. The selective etching of the BST thin film and optimal design of the coupling regions could result in lower insertion loss and improved reflection loss as demonstrated by our group in our earlier work [13]. 


\section{DESIGN}

A schematic diagram of the filter used in this study is shown in Figure 1. The filter was designed to operate as a one-half wavelength resonator at approximately $7.7 \mathrm{GHz}$, with capacitive coupling from the radio frequency (RF) input and output ports to the resonator. The gap between the input/output ports and the resonant section is $165 \mu \mathrm{m}$, chosen for weak coupling. A photograph of the coupled section of the filter is shown in Figure 2. The central resonant section of the filter consists of a $0.494 \mathrm{~cm}$ long, $140 \mu \mathrm{m}$ wide microstrip line, patterned onto a $254 \mu \mathrm{m}$ thick lanthanum aluminate $\left(\mathrm{LaAlO}_{3}\right.$ henceforth LAO) substrate. The dielectric constant $\left(\varepsilon_{\mathrm{r}}\right)$ of LAO is 24 [14], thus the device is expected to operate as a $\lambda \mathrm{g} / 2$ resonator at 7.73 , and as a $\lambda \mathrm{g}$ and $3 \lambda \mathrm{g} / 2$ resonator at approximately 15.5 and $23.2 \mathrm{GHz}$, respectively. In the tunable version of the filter, the ferroelectric film is completely etched from the portion of the resonant section that is not coupled to the input/output lines, nor does the ferroelectric film cover the entire area within the coupling regions between the resonator and input/output lines, as is typical in microstrip design. Instead, the ferroelectric is tapered from the edge of the microstrip lines towards the center of the coupling gap, and has a middle constriction that concentrates the electric field in the constricted area, as shown in Figure 3. The width of the ferroelectric film at the points where it contacts the metal lines is $762 \mu \mathrm{m}$, and the width of the ferroelectric in the center of the coupling gap (i.e. maximum constriction) is $51 \mu \mathrm{m}$. Such a design allows for tunable and weaker coupling, minimizing the coupling losses in the filter. The concept being explored is to demonstrate tunability while minimizing mismatch and dielectric losses, thus improving the overall filter performance.

The basis for this technology is built upon well established electrostatic principles[15]. Starting with the expression for dielectric displacement (D) as a function of electric field $(\mathrm{E})$, dielectric permittivity of free space $\left(\varepsilon_{0}\right)$, and dielectric constant of the medium $(\varepsilon)$, $\vec{D}=\varepsilon_{0} \varepsilon \vec{E}$

For two dielectric regions electrically connected in series,

$\vec{D}_{1}=\vec{D}_{2}$

Thus,

$$
\frac{\varepsilon_{1}}{\varepsilon_{2}}=\frac{\vec{E}_{2}}{\vec{E}_{1}}
$$

Since the ferroelectric film is constricted in the center of the coupling gap, between the input/output and resonator microstrip lines, the effective capacitive coupling is lower in the constricted region than in the regions adjacent to the microstrip lines. Consequently, the DC electric field is concentrated in the constricted region near the center of the coupling gap, as illustrated in Figure 3. Hence, the goal of this work is to utilize selective etching to substantially reduce the effective coupling and loss of the ferroelectric film, 
while maintaining high tunability. Accomplishment of these goals would substantially boost the attractiveness of ferroelectric tuning in high frequency (X-band and above) microstrip circuit elements. This technology could increase the frequency range over which passive microstrip devices (such as filters) useful, since tuning technology would enable precise placement of poles and zeros and thus allow greatly enhanced control over the bandpass or bandstop characteristics[16, 17]. At a more advanced level, tuning technology could enable device reconfiguration - a highly desirable feature for emerging applications such as software defined radio (SDR)[18].

\section{EXPERIMENTAL}

The selectively etched ferroelectric films used to tune the filters consisted of $0.4 \mu \mathrm{m}$ thick $\mathrm{Ba}_{0.50} \mathrm{Sr}_{0.50} \mathrm{TiO}_{3}$ (BSTO) ferroelectric thin films, grown on LAO substrates using pulsed laser deposition (PLD). Standard positive photolithography and wet etching techniques were used to selectively etch the BSTO films. The BSTO was selectively etched in a 1:20 Hydrofluoric acid:deionized (DI) $\mathrm{H}_{2} \mathrm{O}$ solution, and the etch rate was approximately $30 \mathrm{~nm} / \mathrm{min}$. The etched ferroelectric layer is shown in figure 2 . A lift-off photolithographic process was used for the fabrication of the gold filters. A gold layer $\sim 2$ $\mu \mathrm{m}$ was deposited for the ground plane to complete the circuit fabrication.

For RF characterization the filters were tested inside a vacuum chamber to allow for high voltage biasing of the resonator. Voltages up to \pm 400 volts dc could be applied for testing these filters. Since the width of the coupled gaps was $114 \mu \mathrm{m}$, the maximum electric field was 3.5 volts $/ \mu \mathrm{m}$. The transmission and reflection scattering parameters $\left(\mathrm{S}_{21}\right.$ and $\mathrm{S}_{11}$, respectively) were measured at room temperature using an HP $8510 \mathrm{C}$ network analyzer. So as to identify and quantify the loss mechanisms, the types of losses were characterized as insertion loss $\left(\mathrm{L}_{\mathrm{l}}\right)$ reflection loss $\left(\mathrm{L}_{\mathrm{R}}\right)$, mismatch loss $\left(\mathrm{L}_{\mathrm{M}}\right)$, and dissipation loss $\left(\mathrm{L}_{\mathrm{D}}\right)$, where the dissipation losses include conductor, dielectric, and radiation losses. The following formulas were used for evaluation of filter performance [19] :

$$
\begin{aligned}
& \text { insertion loss }(\mathrm{dB})=L_{I}=20 \log S_{21} \\
& \text { reflection loss }(\mathrm{dB})=L_{R}=20 \log S_{\mathrm{I1}} \\
& \text { mismatch loss }(\mathrm{dB})=L_{M}=10 \log \left(1-S_{11}{ }^{2}\right) \\
& \text { dissipation loss }(\mathrm{dB})=L_{D}=10 \log \left(1-\frac{P_{\text {dissipation }}}{P_{\text {in }}}\right)=\mathrm{L}_{I}(\mathrm{~dB})-\mathrm{L}_{\mathrm{M}}(\mathrm{dB})
\end{aligned}
$$

where $P_{\text {in }}$ is the power that is coupled to the resonator $\left(=P_{\text {available }}-P_{\text {mismatch }}\right)$ 


\section{RESULTS}

Experimentally, a nontunable filter containing no ferroelectric materials displayed resonances at 7.9, 15.6, and $23.7 \mathrm{GHz}$, showing fairly good agreement with the model. The nontunable filter is used as a reference for computation of various losses. The tunable filter showed three distinct bandpass regions, corresponding to frequencies at which the filter was $\lambda_{\mathrm{g}} / 2, \lambda_{\mathrm{g}}$, and $3 \lambda_{\mathrm{g}} / 2$ wavelengths long. The presence of the ferroelectric strongly impacted the resonator coupling as well as the tunability. A plot of insertion loss $\left(\mathrm{S}_{21}\right)$ for the bandpass region at $\sim 7.7 \mathrm{GHz}$ is shown in figure 4 . The filter is tunable over the frequency range $7.64-7.84 \mathrm{GHz}$, and the insertion loss varies from 5.5 to $-4.8 \mathrm{~dB}$ over the same frequency range. The corresponding reflection loss $\left(\mathrm{S}_{11}\right.$ and $\mathrm{S}_{22}$ ) data are shown in Figures 5 and 6, respectively. The minimum reflection losses vary from -7 to $-8 \mathrm{~dB}$. Based on these values, the insertion losses corresponding to impedance mismatch ranged from $0.70-0.50 \mathrm{~dB}$, with the remainder attributable to dissipation (conductor, dielectric and radiation) loss. Since the insertion loss of the non-tunable filter is $-4.0 \mathrm{~dB}$, we estimate that the insertion losses directly attributable to dielectric losses in the ferroelectric ranges from approximately -1.5 to $-0.8 \mathrm{~dB}$. The loaded quality factor $\left(\mathrm{Q}_{\mathrm{L}}\right)$ of the resonator varies only a small amount with bias voltage, with small enhancements observed with higher tuning voltages. For tuning voltages of 0,100 , and 400 volts $(=0,0.88$, and 3.55 volts $/ \mu \mathrm{m}), \mathrm{Q}_{\mathrm{L}}$ values are 21,22 , and 26 , respectively. The unloaded $\mathrm{Q}\left(\mathrm{Q}_{\mathrm{U}}\right)$ was calculated using the insertion loss and unloaded $\mathrm{Q}$ values, using the expression

$L_{I}=10 \log \left(1-\frac{Q_{L}}{Q_{U}}\right)^{2}$,

and $\mathrm{Q}_{\mathrm{U}}$ for the resonator at $0,0.88$ and $3.55 \mathrm{~V} / \mu \mathrm{m}$ are 41,48 , and 61 .

Plots showing insertion loss as a function of frequency, taken at temperatures ranging from $200-300 \mathrm{~K}$, are shown in Figures 7 and 8. The data in Figure 7 were taken with no bias voltage applied to the ferroelectric, and the data in Figure 8 were taken at the maximum bias voltage of 400 volts $(=3.5$ volts $/ \mu \mathrm{m})$.

Insertion loss data for the second passband with center frequency at $\sim 15.5 \mathrm{GHz}$, corresponding to the frequency range where the resonator is $\lambda \mathrm{g}$ long, are shown in Figure 9. The filter is tunable from $15.40-15.55 \mathrm{GHz}$, and the insertion loss varies from -3.8 to $-2.8 \mathrm{~dB}$. The reflection loss data are shown in Figures 10 and 11 , and varies from -12 to $14 \mathrm{~dB}$. Using these two sets of data, the loss due to impedance mismatch is calculated to range from -0.50 to $-0.37 \mathrm{~dB}$, with the remainder attributable to dissipation loss. At a bias field of 0.88 volts $/ \mu \mathrm{m}$, where $\mathrm{f}_{\text {res }}=15.5 \mathrm{GHz}, \mathrm{Q}_{\mathrm{L}}$ and $\mathrm{Q}_{\mathrm{U}}$ are 22 and 65 , respectively. Since the insertion loss of the non-tunable filter is higher than that of the tunable filter, it is impossible to separate the ferroelectric losses from the other dissipation losses.

Insertion loss versus frequency, over the temperature range $200-300 \mathrm{~K}$, is shown in Figure 12 (no bias), and Figure 13 (400 volts bias). 
The third bandpass response is centered at $\sim 23.4 \mathrm{GHz}$, corresponding to a resonator length $=3 \lambda_{\mathrm{g}} / 2$. As shown in Figure 14, the filter tunability ranges from $23.35-23.48$ $\mathrm{GHz}$, with minimum insertion losses ranging from -4.8 to $-4.4 \mathrm{~dB}$. The $\mathrm{S}_{11}$ rejection, shown in Figures 15, is excellent. The $\mathrm{S}_{22}$ rejection is shown in Figure 16. Clearly, the $\mathrm{S}_{22}$ rejection is not as low, nor are the transmission poles as well defined as is the case for $\mathrm{S}_{11}$. At the center frequency, the rejection is at least $-20 \mathrm{~dB}$, and sharp, well-formed poles with $\mathrm{S}_{11}$ values that extend below $-30 \mathrm{~dB}$ are clearly visible. The losses attributed to impedance mismatch are negligible-less than $-0.01 \mathrm{~dB}$. At a bias field of 0.88 volts $/ \mu \mathrm{m}$, where $f_{\text {res }}=23.35 \mathrm{GHz}, \mathrm{Q}_{\mathrm{L}}$ and $\mathrm{Q}_{\mathrm{U}}$ are 29 and 68, respectively. The insertion loss of the non-tunable filter at $23.6 \mathrm{GHz}$ is $-3.5 \mathrm{~dB}$, hence the insertion loss directly attributable to the ferroelectric film is in the -1.3 to $-0.9 \mathrm{~dB}$ range. Insertion loss versus frequency, over the temperature range $200-300 \mathrm{~K}$, is shown in Figure 17 (no bias), and Figure 18 (400 volts bias).

\section{DISCUSSION}

A key feature that emerged from this set of experiments is that $\mathrm{Q}_{\mathrm{L}}$ and $\mathrm{Q}_{\mathrm{U}}$ showed only modest variation as a function of tuning voltage within each of the three frequency ranges indicating that the conceptual model outlined in Figure 3 is accurate. Because the RF dielectric loss of tunable ferroelectric films is lower at higher DC bias voltages, the loss in highly constricted region is lower than in the non-constricted regions. Furthermore, the electric field is also concentrated in the central, constricted region, hence the total dielectric loss of the device is dominated by this low-loss region. Even at low tuning voltages, the electric field across the constricted region is considerably higher than in the non-constricted areas of the film, thus creating the low $\varepsilon_{\mathrm{r}}$, low loss region that dominates the electrical performance of the film. Since the constriction is tapered, the width of the low $\varepsilon_{\mathrm{r}}$, low loss central region also varies, thus offering an additional tuning mechanism that complements the traditional tuning mechanism, i.e., to alter the dielectric constant of a uniform ferroelectric film via application of a DC voltage.

This has several implications that are beneficial for high frequency microstrip devices. First, for applications such as coupled microstrip filters, the ability to precisely manipulate the low capacitance levels between coupled microstrip lines offers a powerful technique to control filter frequency, bandwidth, and response. Second, since this approach minimizes dielectric loss, it can be implemented into high frequency designs, thereby extending the frequency range over which small-sized microstrip filters can be used. A third benefit is that that the width of the ferroelectric thin-film adjacent to the microstrip lines can be adjusted so as to produce a uniform charge distribution over the desired microstrip line length. To illustrate this point, if the ferroelectric film is patterned such that the width of the ferroelectric is uniform within the coupled section, but does not extend throughout the coupled section, impedance mismatches arise and the reflection becomes unacceptably high, especially at Ku-band frequencies and higher. 
Comparing data over the frequency ranges where the filters are $\lambda \mathrm{g} / 2, \lambda \mathrm{g}$, and $3 \lambda_{\mathrm{g}} / 2$ long, we see that the $\mathrm{Q}_{\mathrm{L}}$ values are similar, and the $\mathrm{Q}_{U}$ values are higher for the higher frequency $(\lambda \mathrm{g}$ and $2 \lambda \mathrm{g}$ ) tunable filters. Moreover, the tuning range in the lowest frequency $(\lambda g / 2)$ region is higher than for the $\lambda g$ and $3 \lambda_{g} / 2$ regions. This is contrary to the expected behavior for tunable devices that employ traditional tuning mechanisms, wherein the insertion loss and tuning range are expected to increase with increasing frequency, while $\mathrm{Q}_{U}$ and $\mathrm{Q}_{\mathrm{L}}$ decrease. We attribute the observed behavior to the fact tunability is strongly impacted the position of the ferroelectric film along the resonator, with higher tunability (and loss) occurring at positions where the RF voltage is highest. As illustrated in Figure 19, for the frequency range where the resonator is $\lambda \mathrm{g} / 2$ long, the ferroelectric is located near the RF voltage maximum, and there is little variation of the $\mathrm{RF}$ voltage over the length of the ferroelectric region. Where the resonator is $\lambda \mathrm{g}$ long, the RF voltage varies considerably more over the length of the ferroelectric region, and the average RF voltage over the length of the ferroelectric is considerably smaller. This explains the higher $\mathrm{Q}_{U}$ and decreased tuning range, relative to the $\lambda \mathrm{g} / 2$ range. For the frequency range where the resonator is $3 \lambda_{\mathrm{g}} / 2$ long, the ferroelectric extends over a length of the resonator almost $\lambda_{\mathrm{g}} / 4$ long. In addition to tuning the coupling and resonant frequency of the resonator, the ferroelectric is serving as a $1 / 4$ wave transformer, thereby minimizing impedance mismatch losses. Although the tuning is modest, $\mathrm{Q}_{\mathrm{L}}$ is excellent, and the mismatch losses are negligible. The sharp poles in the $\mathrm{S}_{11}$ data with minima below $-30 \mathrm{~dB}$ at frequencies in the $23-24 \mathrm{GHz}$ range, and $\mathrm{S}_{22}$ minima that drop below $17 \mathrm{~dB}$, are appealing for high frequency filter design.

\section{CONCLUSIONS}

Tunable microstrip filters, using selectively etched BSTO ferroelectric layers as the tuning mechanisms, have been shown. The ferroelectric layers were etched so as to concentrate the DC electric fields near the center of the coupling gaps. The approach reduces the coupling between adjacent microstrip lines while still maintaining a high level of tunability. The degree of tunability was correlated with the placement of the ferroelectric, relative to the RF voltage that the ferroelectric experienced. Higher levels of tunability are observed in the frequency range where the microstrip resonator is $\lambda_{\mathrm{g}} / 2$ long, and this is attributed to the ferroelectric behaving essentially as a lumped element varactor, situated near the ends of the open-circuited microstrip line. At higher

frequencies, where the microstrip resonator is $2 \lambda \mathrm{g}$ long, the ferroelectric layer behaves as a $1 / 4$ wave transformer. As a result, mismatch losses are substantially decreased, but only modest tuning is observed. These results show that selectively etched ferroelectric layers can introduce a means to control the precise placement of transmission poles needed to tailor the response of high frequency microstrip filters. 


\section{REFERENCES}

1. F.W. Van Keuls, R.R. Romanofsky, D.Y. Bohman, M.D. Winters, F.A. Miranda, C.H. Mueller, R.E. Treece, T.V. Rivkin, And D. Galt, " $\left.\mathrm{YBa}_{2} \mathrm{Cu}_{3} \mathrm{O}_{7-\delta}, \mathrm{Au}\right) / \mathrm{SrTiO}_{3} / \mathrm{LaAlO}_{3}$ thin film conductor/ferroelectric microstripline phase shifters for phased array applications," Appl. Phys. Lett., vol. 71, pp. 3077-3079 (1997).

2. R.R. Romanofsky, J.T. Bernhard, F.W. Van Keuls, F.A. Miranda, G. Washington, and C. Canedy, "K-band phased array antennas based on $\mathrm{Ba}_{0.60} \mathrm{Sr}_{0.40} \mathrm{TiO}_{3}$ thin-film phase shifters," IEEE Trans. Microwave Theory Tech. vol. 48, pp. 2504-2510 (2000).

3. F.A. Miranda, G. Subramanyam, F.W. Van Keuls, R.R. Romanofsky, J.D. Warner, and C.H. Mueller, "Design and development of ferroelectric tunable microwave components for $\mathrm{Ku}$ - and K-band satellite communication systems," IEEE Trans. Microwave Theory Tech. vol. 48, pp. 1181-1189 (2000).

4. B. Acikel, T.R. Taylor, P.J. Hansen, J.S. Speck and R.A. York, "A new high performance phase shifter using $\mathrm{Ba}_{\mathrm{x}} \mathrm{Sr}_{1-\mathrm{x}} \mathrm{TiO}_{3}$ thin films," IEEE Microwave Wireless Components Lett., vol. 12, p. 237-239 (2002).

5. S. Abadei, A. Deleniv, and S. Gevorgian, "Filter-phase shifters based on thin film ferroelectric varactors," $34^{\text {th }}$ European Mic. Conf., vol. 3, pp. 1493-1496 (2004).

6. G. Vélu, K. Blary, L. Burgnies, J.C. Carru, E. Delos, A. Marteau, and D. Lippens, "A $310^{\circ} / 3 \mathrm{~dB}$ K-band phase shifter using paraelectric BST thin films," IEEE Microwave Wireless Components Lett., vol. 16, p. 87-89 (2006).

7. G. Subramanyam, F.W. Van Keuls, and F.A. Miranda, "A K-band-frequency agile microstrip filter using a thin-film HTS/ferroelectric/dielectric multilayer configuration," IEEE Trans. Microwave Theory Tech. vol. 48, pp. 525-530 (2000).

8. G. Subramanyam, N. Mohsina, A. Zaman, F.W. Van Keuls, F.A. Miranda, R.R. Romanofsky, J.D. Warner, and C. Chen, "Design and development of ferroelectric tunable coplanar waveguide components for $\mathrm{Ku}$ - and K-band applications," Integrated Ferroelectrics, vol. 42, pp. 151-163 (2002).

9. R.A. Walters, A. Centeno, P.K. Petrov, and N. McAlford, "Tuneable end-coupled ferroelectric-gap filters based on barium strontium titanate capacitors," Asia-Pacific Conf. Applied Electromagnetics Proc., pp. 250- 252 (2005).

10. P. Scheele, A. Giere, S. Mueller, and R. Jakoby, "Microwave switches based on tunable ferroelectric filters," IEEE Radio and Wireless Symp., pp. 591-594 (2006). 
11. G. Subramanyam, F.A. Miranda, F.W. Van Keuls, R.R. Romanofsky, C.L. Canedy, S. Aggarwal, T. Venkatesan, and R. Ramesh, "Performance of a K-band voltagecontrolled lange coupler using a ferroelectric tunable microstrip configuration," IEEE Microwave Guided Wave Lett., vol. 10, pp. 136-138 (2000).

12. C.H. Mueller, R.R. Romanofsky, and F.A. Miranda, "Ferroelectric thin film and broadband satellite systems," IEEE Potentials, pp. 36-39 (April/May, 2001).

13. F.A. Miranda, C.H. Mueller, F.W. Van Keuls, G. Subramanyam, and s. Vignesparamoorthy, "Performance enhancement of tunable bandpass filters using selective etched ferroelectric thin films," Integrated Ferroelectrics, vol. 50, pp. 121-131 (2002).

14. C. Zuccaro, M. Winter, N. Klein, and K. Urban, "Microwave absorption in single crystals of lanthanum aluminate,” J. Appl. Phys., vol. 82, pp. 5695-5704(1997).

15. S. Ramo, J.R. Whinnery, T. Van Duzer, Fields and Waves in Communication Electronics. New York, New York: John Wiley and Sons, 1994.

16. S. Winder, Filter Design. Oxford: Newnes, 1997.

17. J.A.G. Malherbe, Microwave Transmission Line Filters. Dedham, MA: Artech (1980).

18. W.M. Fathelbab and M.B. Steer, "A reconfigurable bandpass filter for RF/microwave multifunctional systems," IEEE Trans. Microwave Theory Tech. vol. 53, pp. 1111-1116 (2005).

19. P.A. Rizzi, Microwave Engineering Passive Circuits. Englewood Cliffs, NJ: Prentice Hall (1988). 


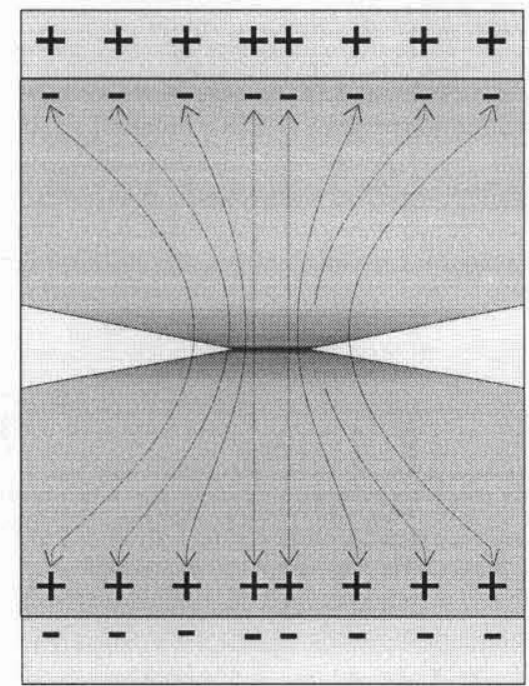

Figure 3. Sketch illustrating enhancement of the electric field in the constricted portion of the ferroelectric film. Darker red color corresponds to higher DC electric fields, and subsequently lower $\varepsilon_{\mathrm{r}}$ and tan $\delta$ values for the ferroelectric film. The electric field lines, and thus the overall tunability and $\tan \delta$ of the ferroelectric film, are dominated by the constricted portion of the film. 


\section{FIGURES}

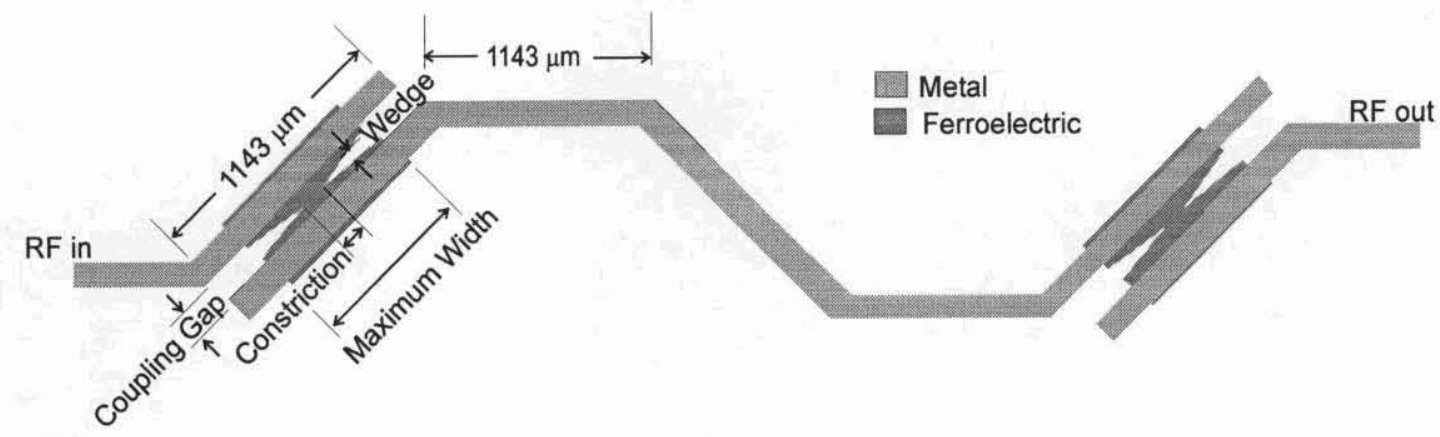

Figure 1. One-pole microstrip filter with etched ferroelectric layer. The ferroelectric layer is $732 \mu \mathrm{m}$ wide where it contacts the metallization, and constricts to $51 \mu \mathrm{m}$ wide in the center of the gap. The coupling gap between the resonator and the RF input/output coupling lines is $114 \mu \mathrm{m}$. The wedge gap (= distance within the coupling gap over which the ferroelectric is constricted) is $64 \mu \mathrm{m}$.

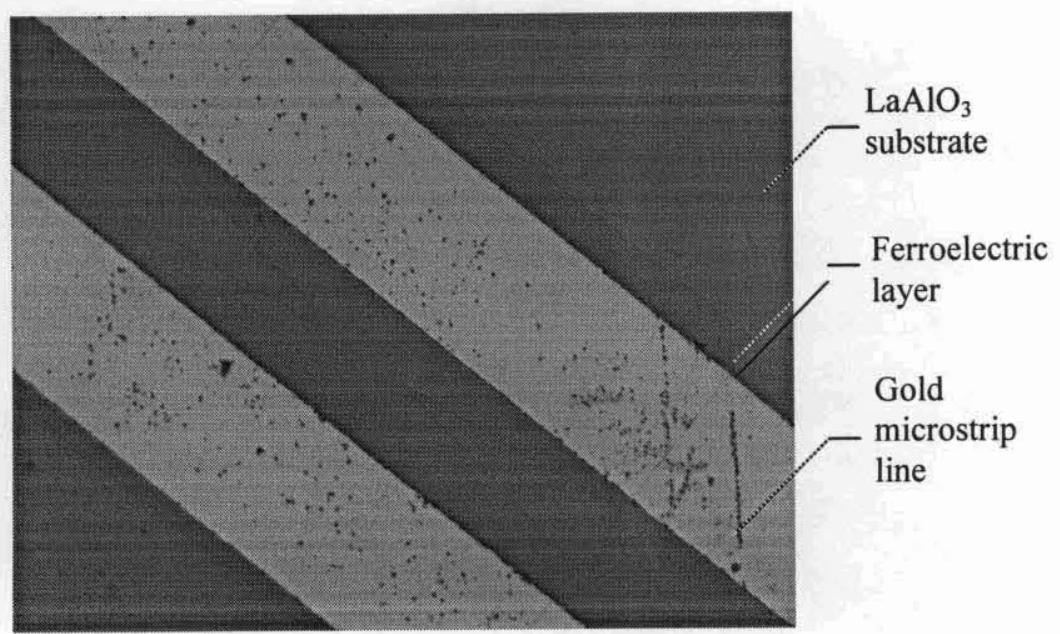

Figure 2. Coupled section of filter, showing etched ferroelectric layer 


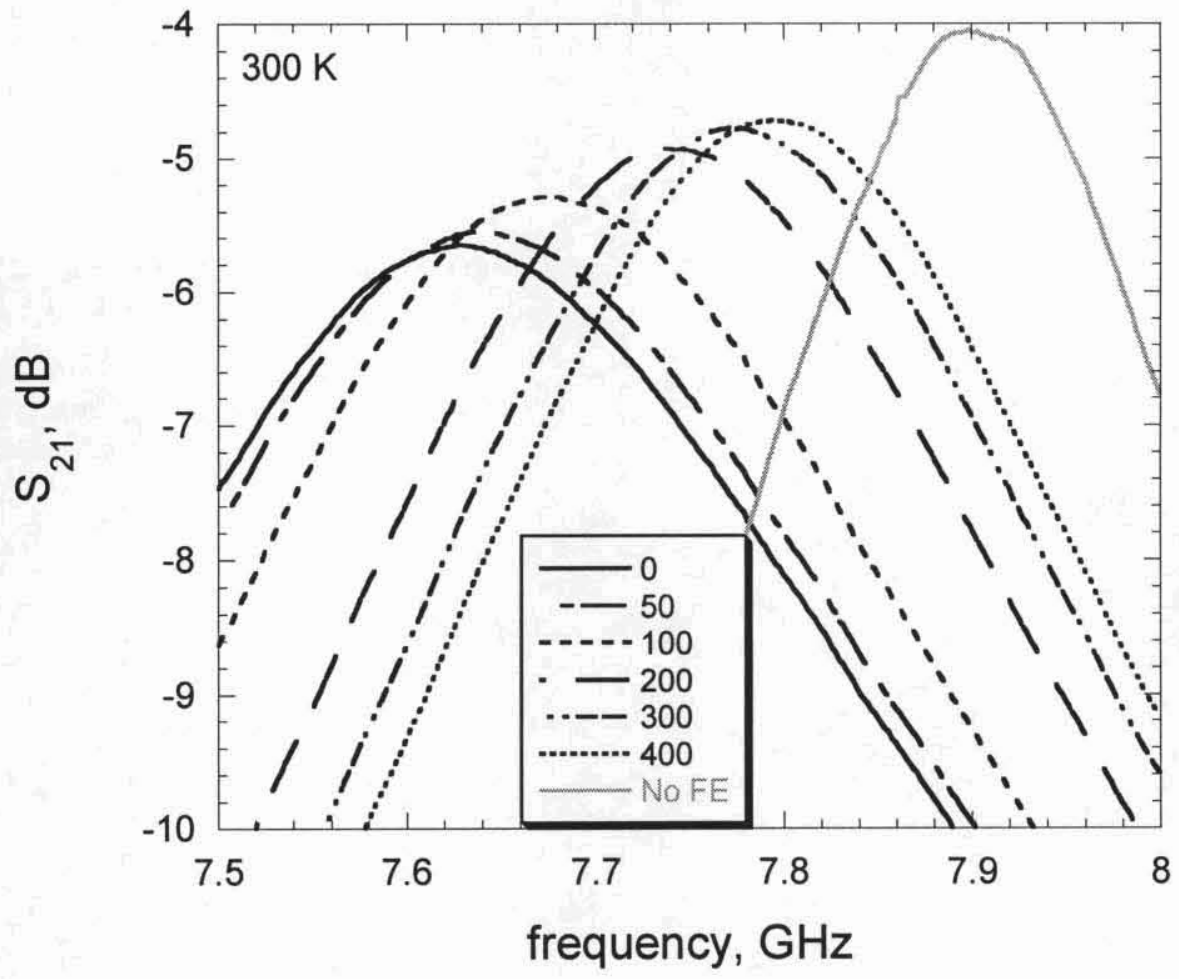

Figure 4. Insertion loss $\left(\mathrm{S}_{21}\right)$ as a function of frequency, over the frequency range where the resonators are $\lambda_{\mathrm{g}} / 2$ long. The tuning range is $180 \mathrm{MHz}$. Also shown is the response of a non-tunable filter that is identical to the tunable version, but fabricated without the ferroelectric layer. 


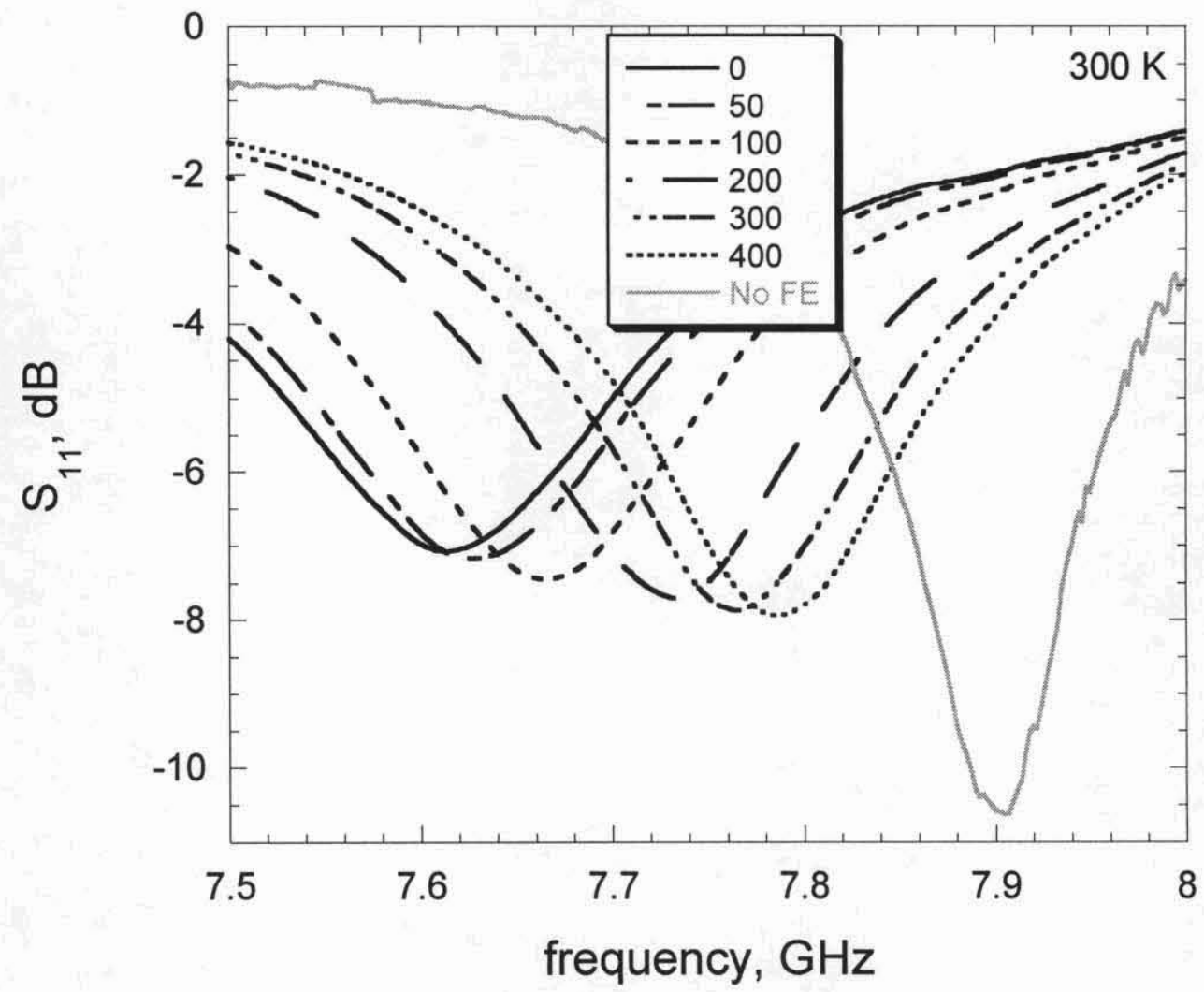

Figure 5. Return loss $\left(\mathrm{S}_{11}\right)$ as a function of frequency, over the frequency range where the resonators are $\lambda_{\mathrm{g}} / 2$ long. 


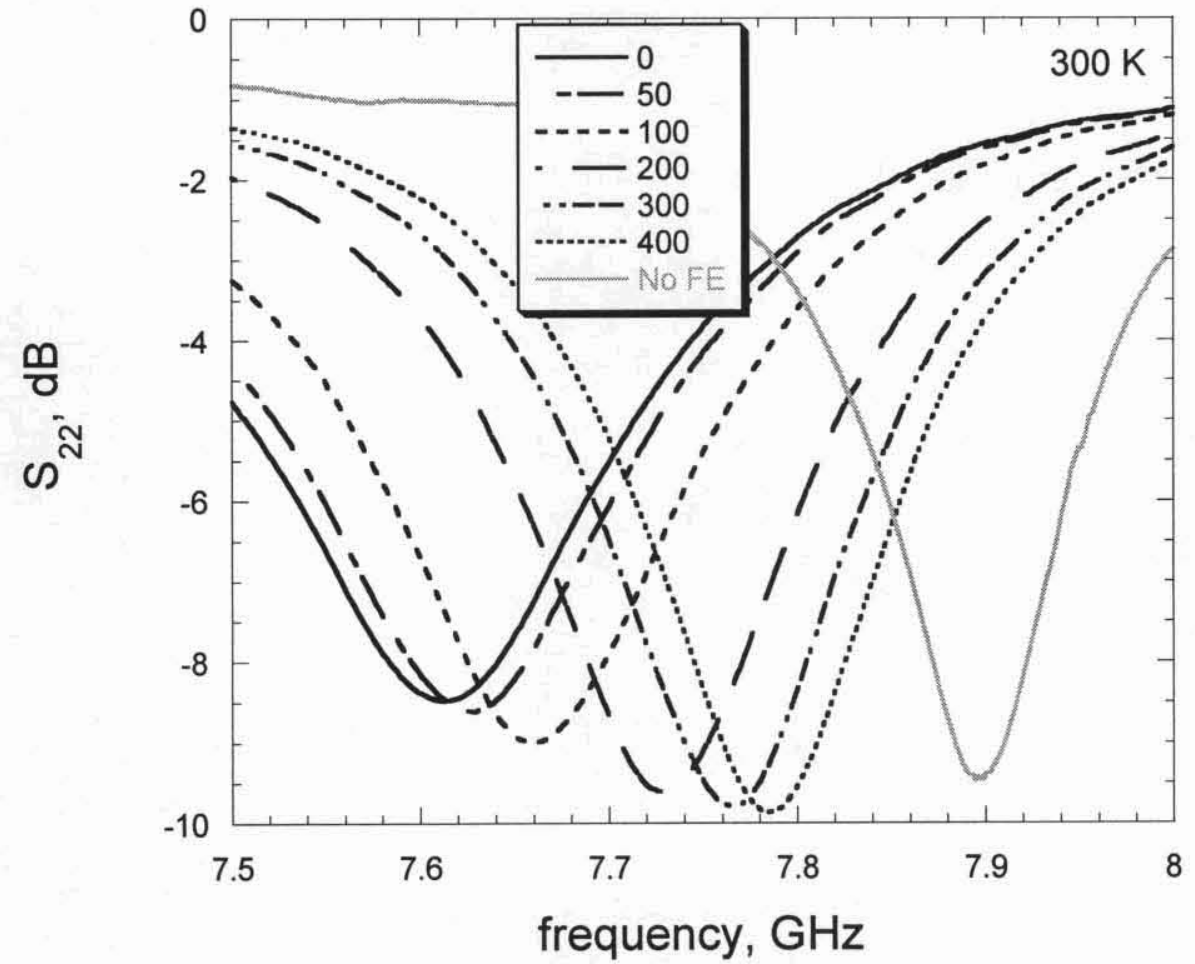

Figure 6. Return loss $\left(\mathrm{S}_{22}\right)$ as a function of frequency, over the frequency range where the resonators are $\lambda_{\mathrm{g}} / 2$ long. 


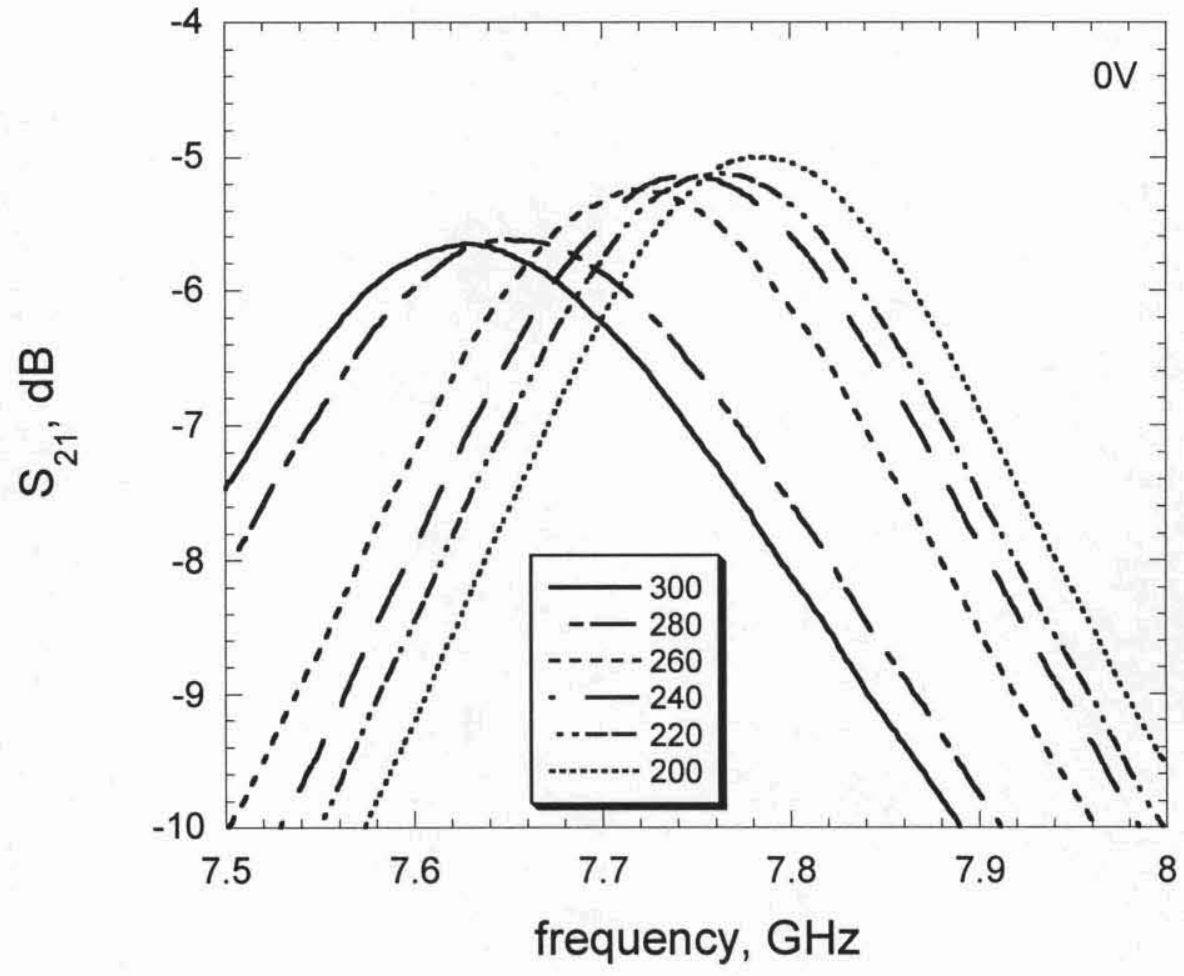

Figure 7. Insertion loss $\left(\mathrm{S}_{21}\right)$ as a function of frequency, over the frequency range where the resonators are $\lambda \mathrm{g} / 2$ long. Data taken with no voltage bias, over temperatures ranging from 200 to $300 \mathrm{~K}$. 


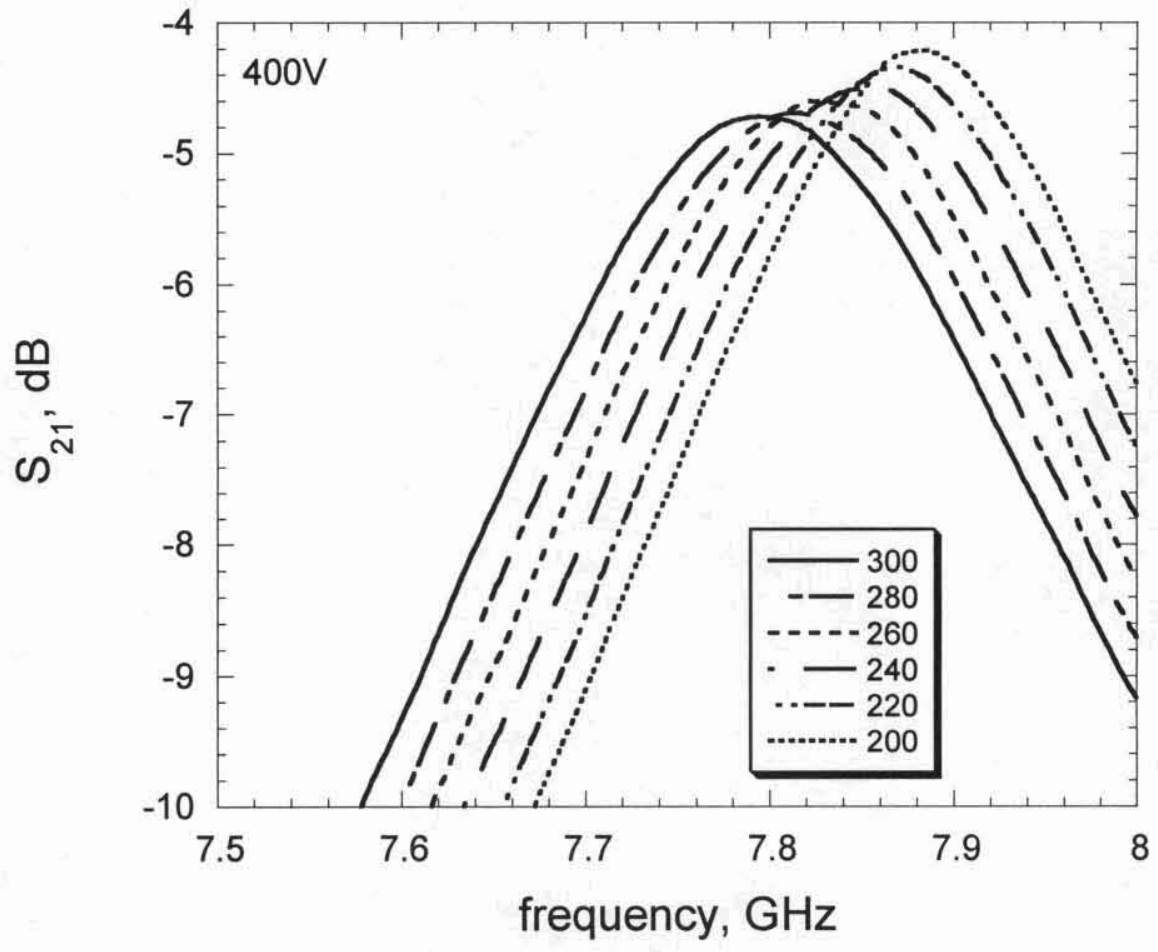

Figure 8. Insertion loss $\left(\mathrm{S}_{21}\right)$ as a function of frequency, over the frequency range where the resonators are $\lambda_{\mathrm{g}} / 2$ long. Data taken at a bias voltage of 400 volts, over temperatures ranging from 200 to $300 \mathrm{~K}$. 


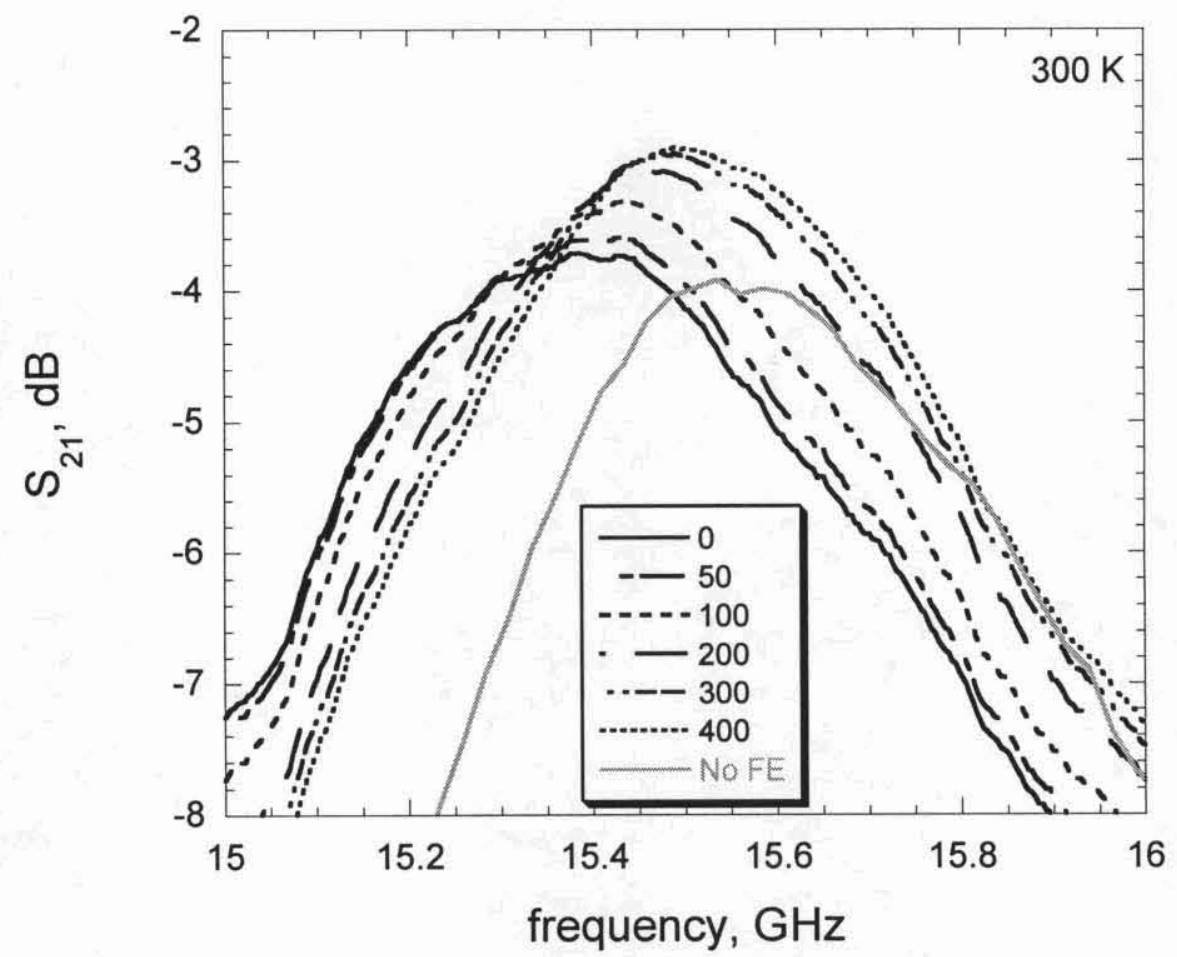

Figure 9. Insertion loss $\left(\mathrm{S}_{21}\right)$ as a function of frequency, over the frequency range where the resonators are $\lambda_{\mathrm{g}}$ long. The tuning range is $120 \mathrm{MHz}$. 


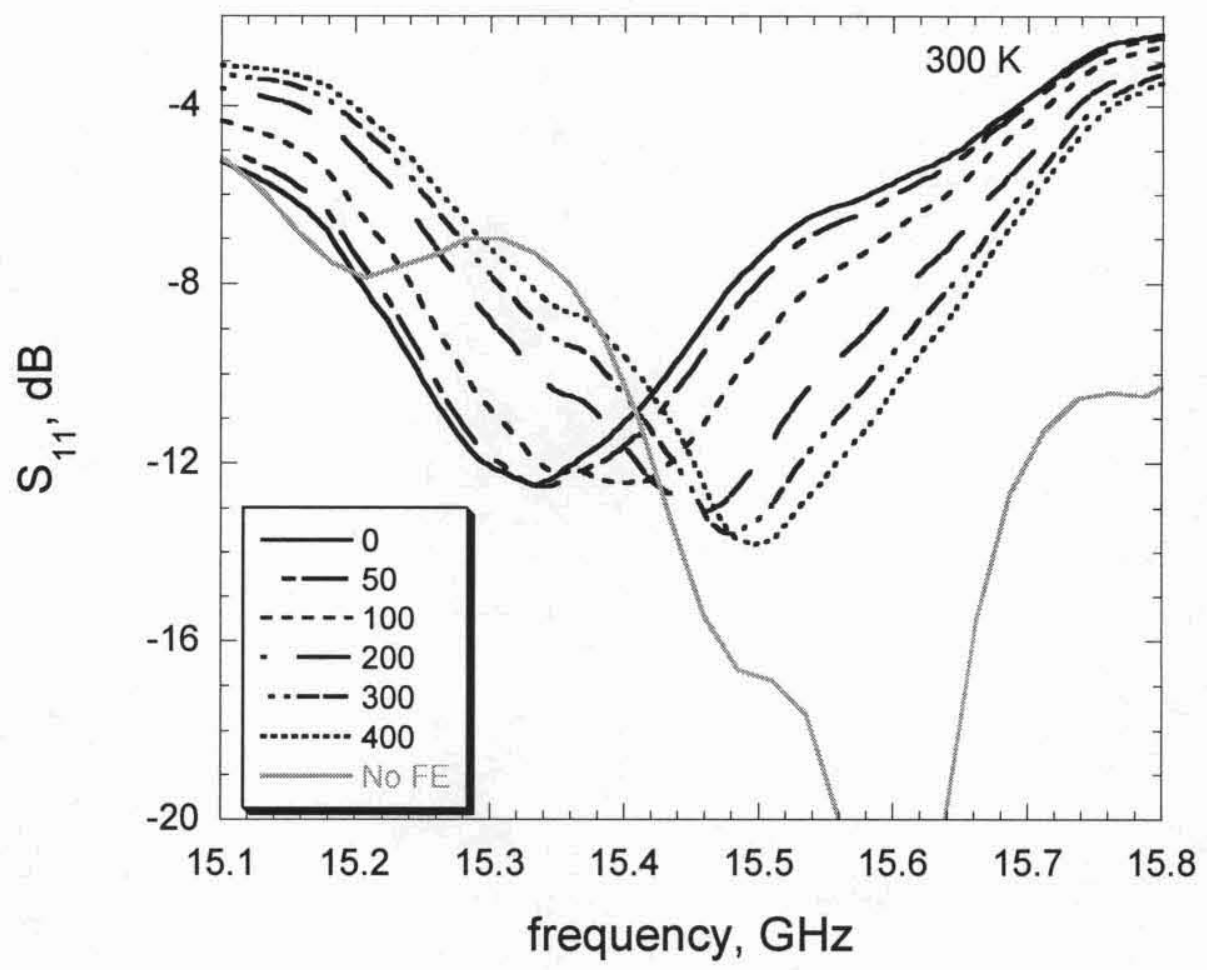

Figure 10. Return loss $\left(\mathrm{S}_{11}\right)$ as a function of frequency, over the frequency range where the resonators are $\lambda_{\mathrm{g}}$ long. 


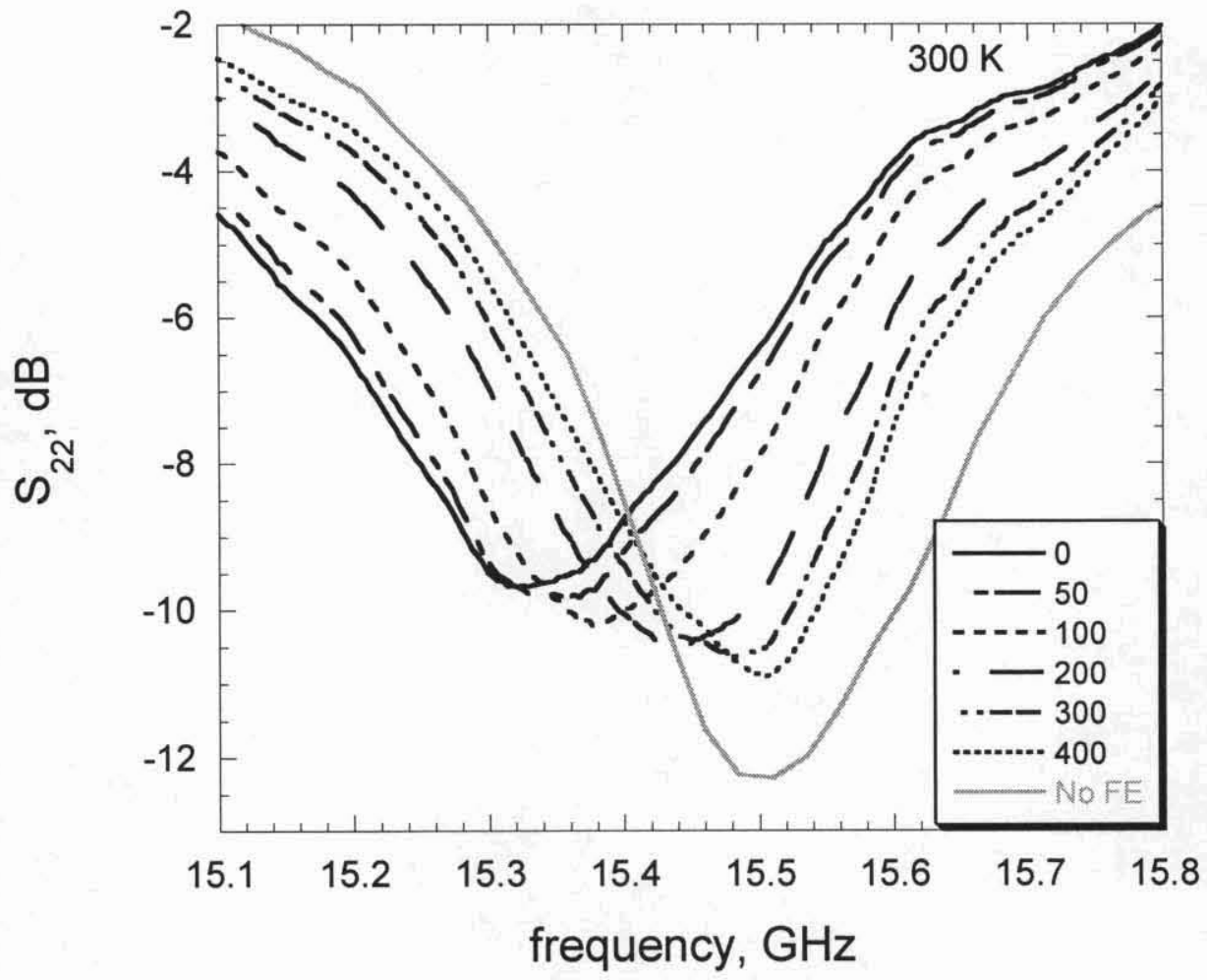

Figure 11. . Return loss $\left(\mathrm{S}_{22}\right)$ as a function of frequency, over the frequency range where the resonators are $\lambda_{\mathrm{g}}$ long. 


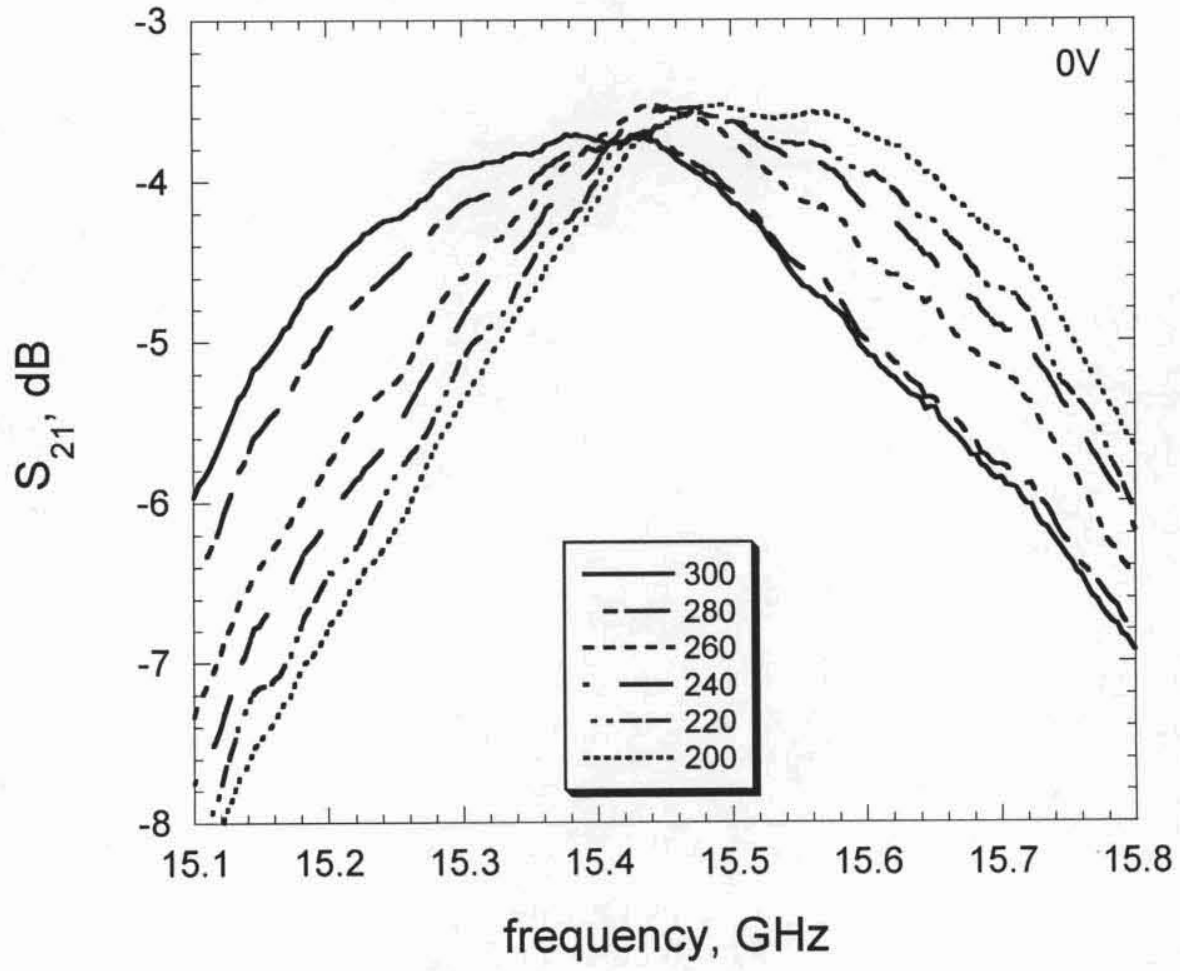

Figure 12. . Insertion loss $\left(\mathrm{S}_{21}\right)$ as a function of frequency, over the frequency range where the resonators are $\lambda_{\mathrm{g}}$ long. Data taken with no voltage bias, over temperatures ranging from 200 to $300 \mathrm{~K}$. 


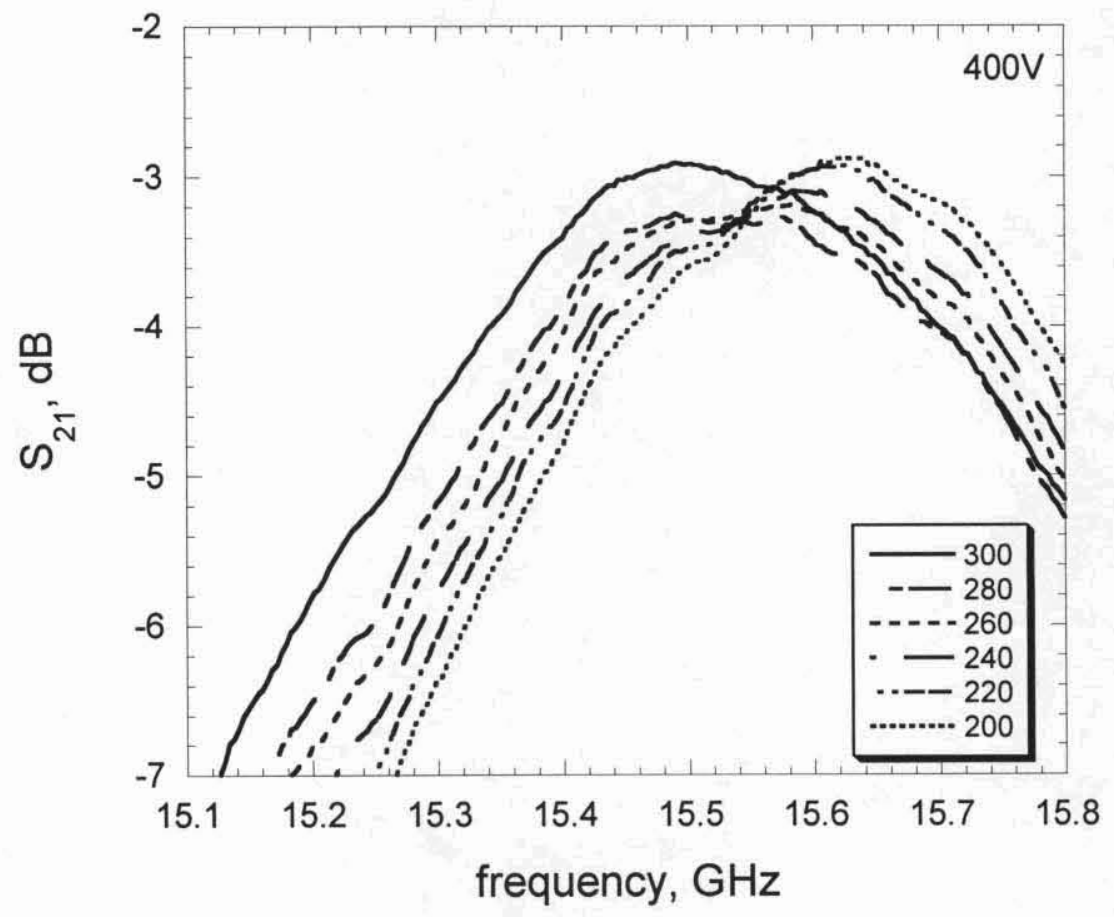

Figure 13. . Insertion loss $\left(\mathrm{S}_{21}\right)$ as a function of frequency, over the frequency range where the resonators are $\lambda_{\mathrm{g}}$ long. Data taken at a bias voltage of 400 volts, over temperatures ranging from 200 to $300 \mathrm{~K}$. 


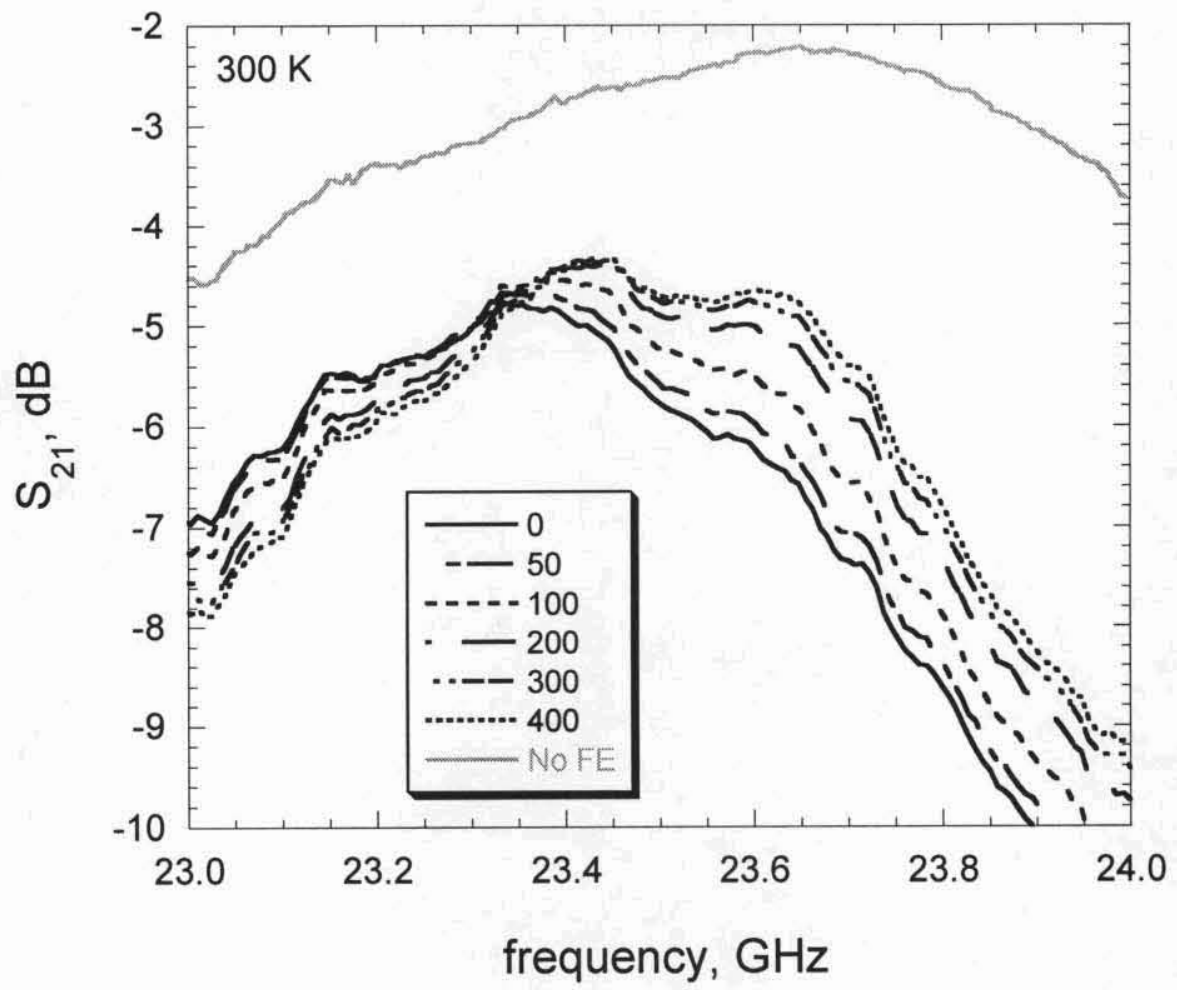

Figure 14. Insertion loss $\left(\mathrm{S}_{21}\right)$ as a function of frequency, over the frequency range where the resonators are $2 \lambda_{\mathrm{g}}$ long. The tuning range is approximately $100 \mathrm{MHz}$. 


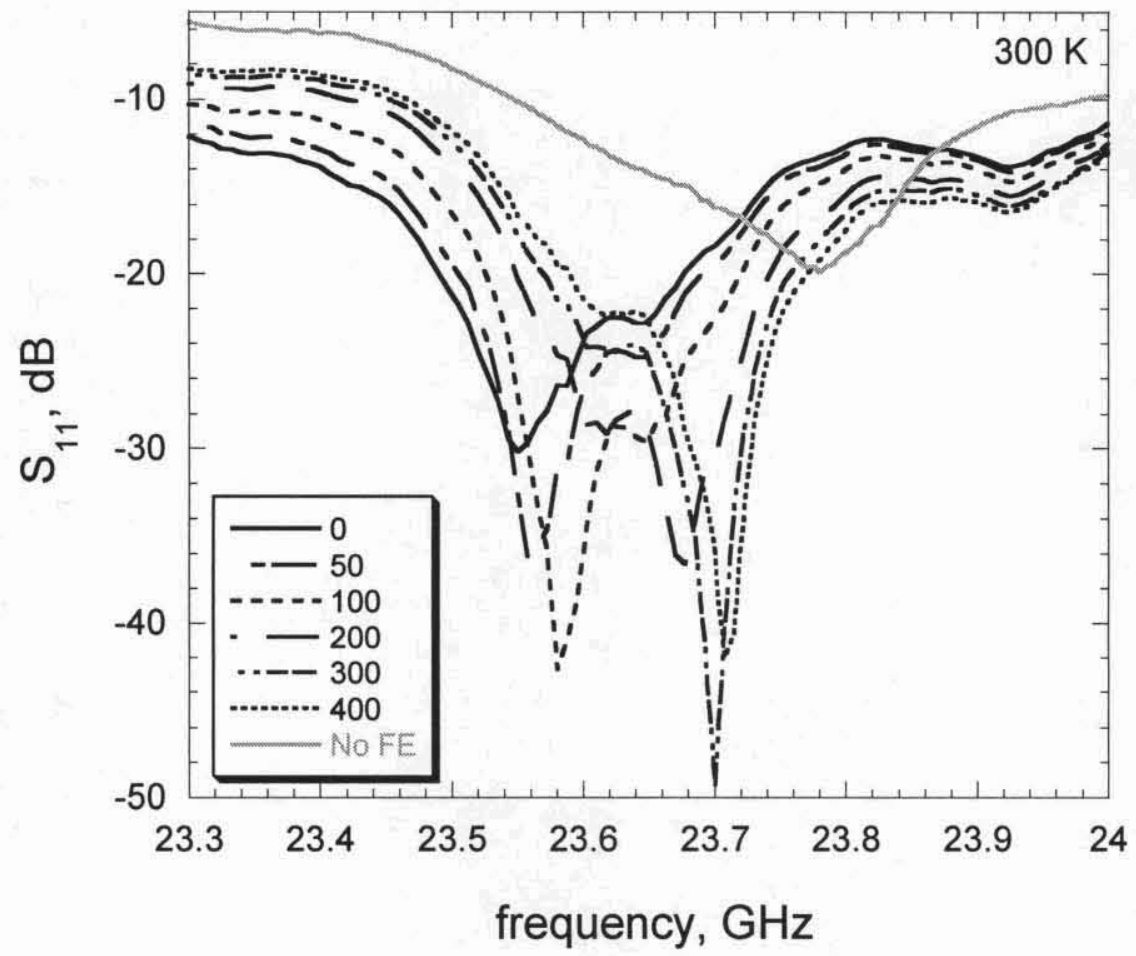

Figure 15. Return loss $\left(\mathrm{S}_{11}\right)$ as a function of frequency, over the frequency range where the resonators are $2 \lambda_{\mathrm{g}}$ long. 


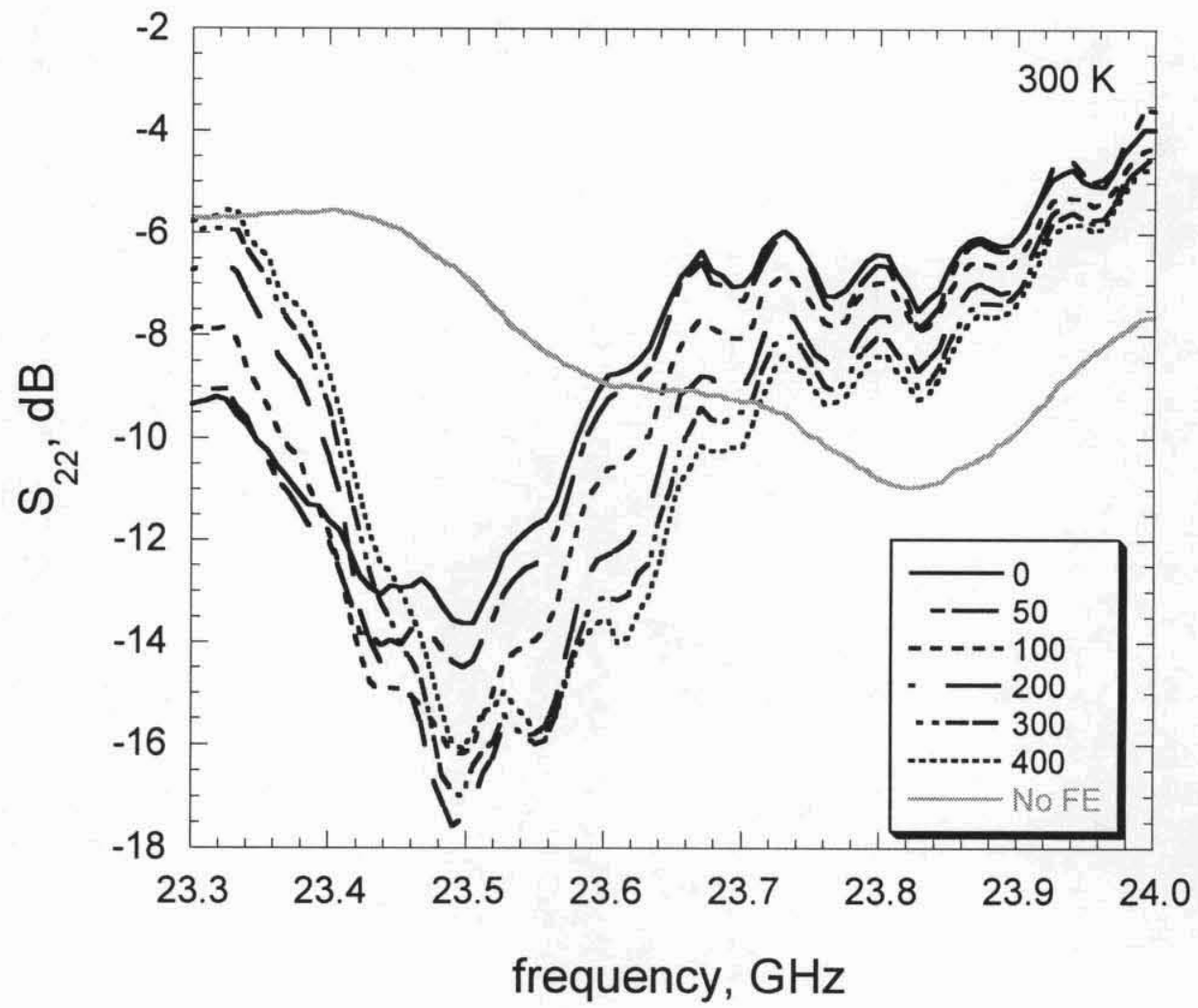

Figure 16. Return loss $\left(\mathrm{S}_{22}\right)$ as a function of frequency, over the frequency range where the resonators are $2 \lambda_{\mathrm{g}}$ long. 


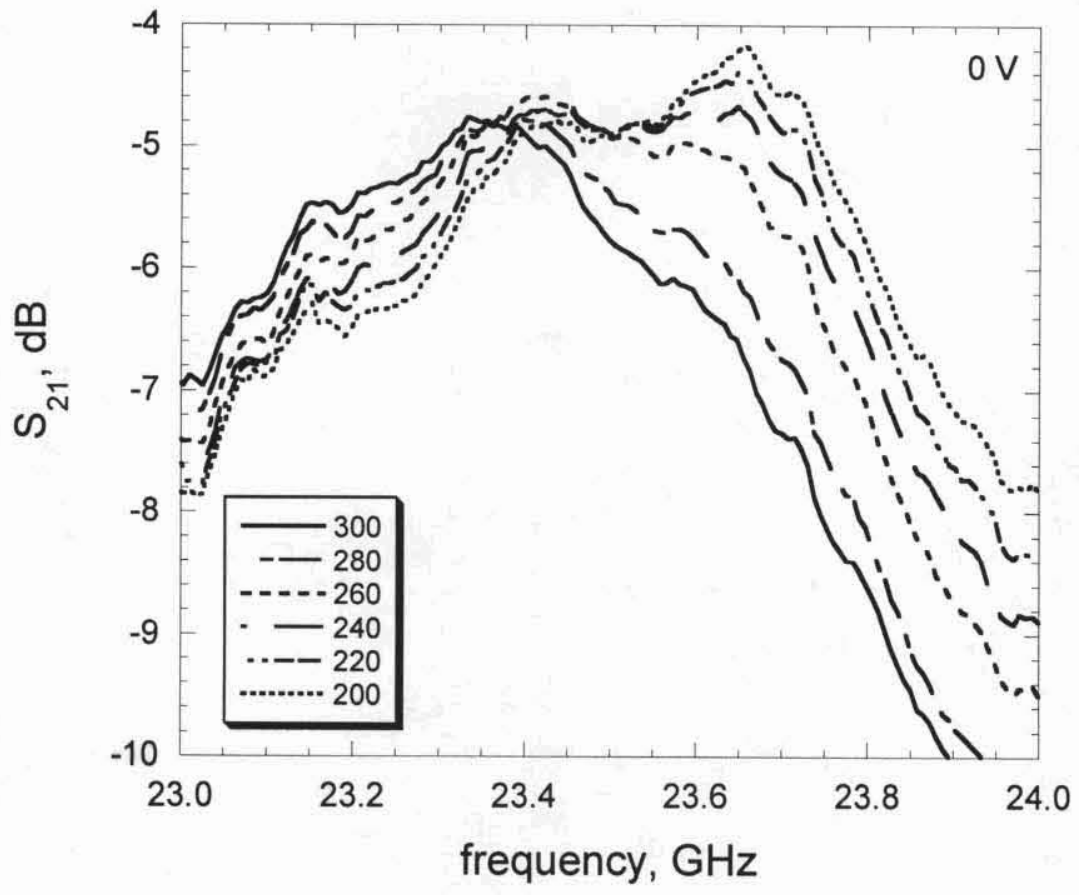

Figure 17. Insertion loss $\left(\mathrm{S}_{21}\right)$ as a function of frequency, over the frequency range where the resonators are $2 \lambda_{\mathrm{g}}$ long. Data taken with no voltage bias, over temperatures ranging from 200 to $300 \mathrm{~K}$. 


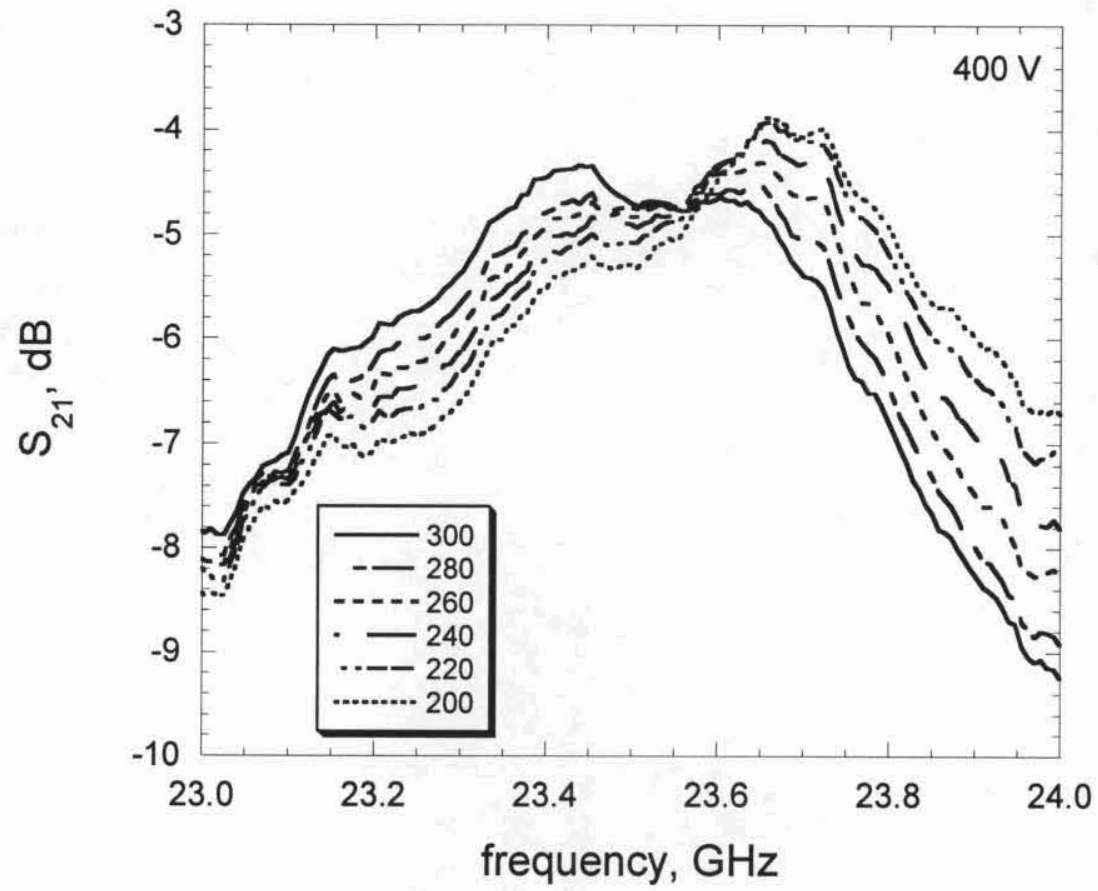

Figure 18. . Insertion loss $\left(\mathrm{S}_{21}\right)$ as a function of frequency, over the frequency range where the resonators are $2 \lambda_{\mathrm{g}}$ long. Data taken at a bias voltage of 400 volts, over temperatures ranging from 200 to $300 \mathrm{~K}$. 


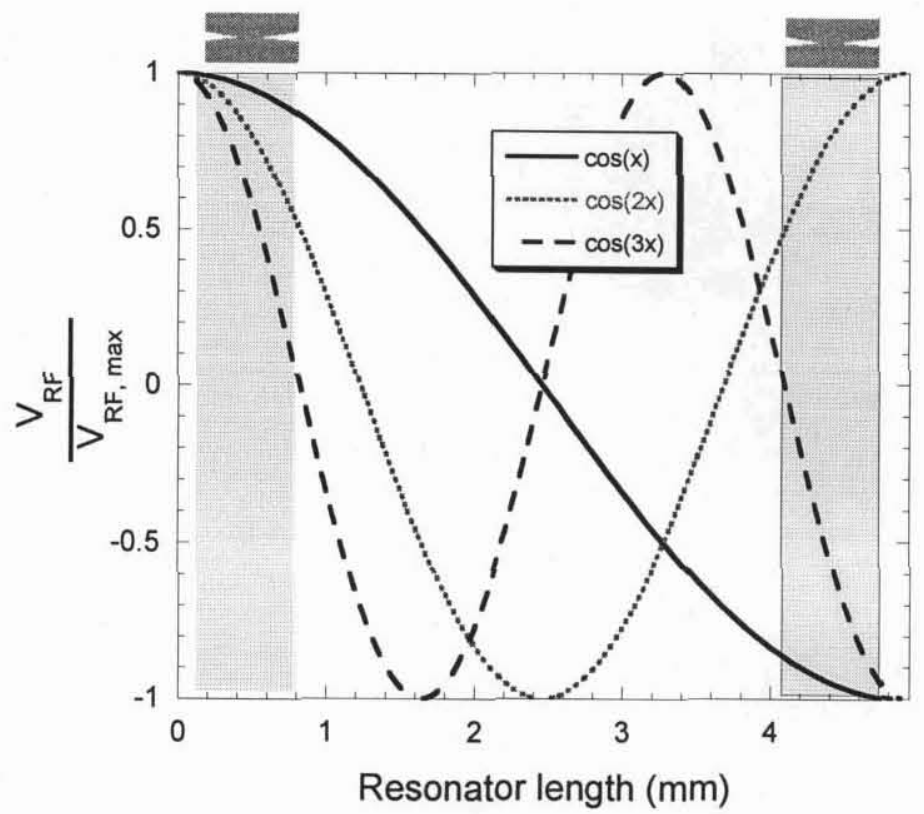

Figure 19. Schematic diagram showing the distribution of the RF voltage over the length of the resonator. The graphs for $\cos (x), \cos (2 x)$, and $\cos (3 x)$ are intended to approximate the voltage profile over the length of the resonator, where the resonator is $\lambda \mathrm{g} / 2, \lambda \mathrm{g}$, and $3 \lambda \mathrm{g} / 2$ wavelengths long, respectively. The grey area denotes the area over which the ferroelectric region is coupled to the resonator. Note that for the $3 \lambda \mathrm{g} / 2$ resonant length, the ferroelectric layer is approximately $\lambda \mathrm{g} / 4$ long. 